\title{
Effect of Natural Fermentation of Sorghum on Resistant Starch Molecular Structure and Fermentation Property
}

\author{
YunFei Ge, ${ }^{1}$ WeiHao Wang, ${ }^{1,2}$ Meng Shen ${ }^{10},{ }^{1}$ ZiYue Kang, ${ }^{1}$ Juan Wang, ${ }^{1}$ ZhiGang Quan, \\ JinLing Xiao,, ${ }^{1}$ ShuTing Zhao, ${ }^{1}$ DeZhi Liu, ${ }^{1}$ and LongKui Cao $\mathbb{1}^{1,2}$ \\ ${ }^{1}$ College of Food Science, Heilongjiang Bayi Agricultural University, Xinfeng Lu 5, Daqing 163319, China \\ ${ }^{2}$ National Engineering Research Center for Coarse Grains, Heilongjiang Bayi Agricultural University, Daqing 163319, China \\ Correspondence should be addressed to LongKui Cao; caolongkui20190606@163.com
}

Received 5 June 2019; Accepted 17 February 2020; Published 16 March 2020

Academic Editor: Ajaya Kumar Singh

Copyright (c) 2020 YunFei Ge et al. This is an open access article distributed under the Creative Commons Attribution License, which permits unrestricted use, distribution, and reproduction in any medium, provided the original work is properly cited.

\begin{abstract}
Relevant research results have suggested that fermentation can increase the content of sorghum amylose chains and their retrogradation value. Therefore, this study explored the effect of fermentation pretreatment on the yield, digestibility, molecular structure, and in vitro fermentation property of sorghum-resistant starch by conducting fermentation pretreatment of sorghum and extracting the resistant starch from fermented sorghum with pressure-heat compound enzyme method. The results were as follows. After fermentation pretreatment, the yield of sorghum-resistant starch increased, the digestibility of sorghum-resistant starch reduced, the laminated structure size on the surface of the particles became more uniform, and the stacking mode became more neat and denser. The sorghum-resistant starch prepared before and after fermentation did not produce new chemical groups, and its functional group peak remained unchanged. After fermentation, the weight-average molecular weight of sorghum-resistant starch was elevated, and the percentage content of high- and low-molecular substances increased and decreased, respectively, compared with that of the unfermented sorghum-resistant starch. The percentage content of short-chain branches in the branched chain increased, whereas that of the long-chain branches decreased; the crystallinity of sorghum-resistant starch after fermentation decreased, and the intensity of X-diffraction peak changed slightly before and after fermentation. According to the results of the in vitro fermentation experiments, the fermentation broth of sorghum-resistant starch had the highest content of butyric acid and short-chain fatty acid. Research results reveal that, after fermentation pretreatment, sorghum-resistant starch presented increased yield, more complex molecular structure, heavier molecular weight and more uniform surface morphology, more efficient butyric acid generation, and greater fermentation rate than unfermented sorghum-resistant starch.
\end{abstract}

\section{Introduction}

Sorghum is also known as durra, sorghum rice, sorgo, and so on [1]. It has been honored as "the essence of the five cereals and the king of grains" since ancient times [2]. Sorghum, China's fifth food crop has gained immense importance in the national economy, considering its high yield and high stress resistance in the face of increasing population and gradually depleting fresh water resources [3].

Starch is the major carbohydrate in sorghum with a content up to $80 \%$. Compared with other cereals, the digestibility of sorghum starch is low. The antinutrients such as tannin in sorghum limit the digestion and absorption of sorghum starch [4], whereas the natural-resistant starch (RS) in sorghum influences its digestibility. Resistant starch as an insoluble dietary fiber [5] has attracted immense attention of domestic and overseas scholars owing to its strong biological activity. Presently, corn, rice, wheat, and other crops are popular research targets; however, few researchers have focused on sorghum-resistant starch. China boasts about abundant sorghum resources of rich varieties; however, most are used in feed and brewing industries, which is not a 
complete exploitation of the economic potential of this crop. Fermentation serves as one of the major means of enhancing food flavor, expanding the application scope of cereals and improving their utilization ratio. Existing related research results have revealed that fermentation can increase the content of sorghum amylose and its retrogradation value [6]. In addition, Abd et al. [7] reported that natural fermentation of sorghum greatly increased the content of lysine, leucine, isoleucine, and methionine. Therefore, fermentation pretreatment-based preparation of sorghum-resistant starch not only endows resistant starch with certain physiological functions but also increases its yield, expands its application, and improves its economic value.

This study carried out natural fermentation of sorghum to extract sorghum starch and prepare resistant starch through the pressure-heat compound enzyme method. Gel chromatography-differential-multiangular laser light scattering spectrometer, ICS-5000 ion chromatograph, X-ray diffraction analyzer, Fourier transform infrared spectrometer, and few other equipment were used to study the effect of fermentation on the yield, molecular structure, and fermentation property of sorghum-resistant starch with an aim to provide theoretical basis and data support for application of fermentation-based preparation of sorghum-resistant starch.

\section{Materials and Methods}

2.1. Experimental Material. Sorghum: Sorghum R of Linyi, Shandong. Hydrochloric acid and sodium oxide (analytically pure), seignette salt (analytically pure), phenol (analytically pure), potassium dihydrogen phosphate (analytically pure), potassium bromide (spectral level), high temperatureresistant $\alpha$-amylase $(1400 \mu / \mathrm{g})$, pullulanase (1000 ASPU/g), trypsin $(190,000 \mu / \mathrm{mg})$, pepsase $(15,000 \mu / \mathrm{g})$, glucoamylase $(100,000 \mu / \mathrm{g})$, and 3,5-dinitrosalicylic acid were all purchased from Tianjin Damao Chemical Reagent Factory (Tianjin, China). Glucan standards, formic acid, acetic acid, propionate, and butyric acid (standards) were purchased from Sigma (Shandong, China). Anaerobic gas bag and anaerobic culture bag were purchased from Qingdao Hope Bio-Technology Co., Ltd. (Shandong, China). Distilled water was prepared in the laboratory.

2.2. Instruments and Equipment. Dgg-9053A electrothermal blowing dry box was provided by Samsung Laboratory Instrument Co., Ltd. (Shanghai, China), MJ-10A flour mill by Puheng Information Technology Co., Ltd. (Shanghai, China), scanning electron microscope by Dutch FEI company (Shanghai, China), Nicolet 6700 Fourier transform infrared spectrometer by US Thermo Fisher (Shanghai, China), gel chromatography-differential-multiangular laser light scatter and Waters1525 high-performance gas chromatograph by US Waters (Shanghai, China), ICS-5000 ion chromatograph by US Dionex (Shanghai, China), UV Spectrophotometer by General Analysis General Instruments Co., Ltd. (Beijing, China), and LS-3781L-PC autoclave by Panasonic Medical Devices Co., Ltd. (Shanghai, China).

\subsection{Experimental Method}

2.3.1. Natural Fermentation of Sorghum. About $150 \mathrm{~g}$ of sorghum was washed with distilled water thrice; next, $300 \mathrm{~mL}$ of distilled water and $4.5 \mathrm{~g}$ of glucose were added, and the solution was naturally fermented for 8 days at $30^{\circ} \mathrm{C}$.

2.3.2. Starch Preparation of Naturally Fermented Sorghum. The fermented sorghum was washed with water and dried at $35^{\circ} \mathrm{C}$; thereafter, the sorghum flour was subjected to dry grinding, was then sieved with an 80 -mesh sieve, and was immersed in $\mathrm{NaOH}$ solution of $0.3 \mathrm{~g} / 100 \mathrm{~mL}$ in a ratio of 1 : $3 \mathrm{~g} / \mathrm{mL}$ for $3 \mathrm{~h}$. Furthermore, this solution was centrifuged for $10 \mathrm{~min}$ at $4000 \mathrm{rpm}$, and the supernatant and upper-layer tawny substance were removed. Next, the solution was washed four times continuously and centrifuged until the starch slurry became white. The $\mathrm{pH}$ of the starch slurry was regulated to 7.0 with $1 \mathrm{~mol} / \mathrm{L} \mathrm{HCl}$, centrifuged, dried at $30^{\circ} \mathrm{C}$, and screened with an 80-mesh sieve [8].

\subsubsection{Resistant Starch Preparation of Naturally Fermented} Sorghum. One hundred grams of sorghum starch was weighed before and after fermentation; to this, $1000 \mathrm{~mL}$ of water was added to prepare starch milk. Next, the starch milk was placed in an autoclave for pressure-heat for $15 \mathrm{~min}$ under $115^{\circ} \mathrm{C}$, removed and then cooled down to $40^{\circ} \mathrm{C}$; the $\mathrm{pH}$ was regulated to 4.5. Moreover, $3 \mathrm{U} / \mathrm{g}$ pullulanase was treated for $8 \mathrm{~h}$ at $40^{\circ} \mathrm{C}$ before enzyme deactivation for $15 \mathrm{~min}$ at $95^{\circ} \mathrm{C}$; thereafter, the sample was removed and cooled to $20-25^{\circ} \mathrm{C}$, and the roughly extracted sorghum-resistant starch was removed [9].

\subsubsection{Content Determination of Resistant Starch in Naturally Fermented Sorghum}

(1) Drawing of Glucose Standard Curve. In general, $0.1 \mathrm{~g}$ of anhydrous glucose was placed into a beaker and then dried in a drying oven at $105^{\circ} \mathrm{C}$ to reach a constant weight; the solution was then dissolved with a small amount of distilled water and transferred to a volumetric flask of $100 \mathrm{~mL}$, to which distilled water was added to attain a constant volume and to get the glucose standard solution of $1 \mathrm{mg} / \mathrm{mL}$. Moreover, $0.0,0.2,0.4,0.6,0.8,1.0$, and $1.2 \mathrm{~mL}$ of the aforementioned glucose standard solution was poured into 7 standard $25 \mathrm{~mL}$ test tubes and 2.0, 1.8, 1.6, 1.4, 1.2, 1.0, and $0.8 \mathrm{~mL}$ of distilled water was added to these tubes, respectively; next, $1.5 \mathrm{~mL}$ of 3,5-Edlefsen reagent was added. This solution was then heated in boiling water for $5 \mathrm{~min}$ after being evenly mixed and was then quickly cooled to room temperature with cold water; to this solution, distilled water was added to attain a constant volume of $25 \mathrm{~mL}$ and was shaken well. The test tube with no glucose solution was used as a blank control. Colorimetric determination was conducted at $540 \mathrm{~nm}$, and the absorbance value was recorded. The glucose in milligram is used as abscissa, whereas the absorbance value is used as ordinate to draw the standard curve [10]. 
(2) Content Determination of Resistant Starch. About $2.00 \mathrm{~g}$ of roughly extracted sorghum-resistant starch sample was accurately weighed before and after fermentation and was poured into a triangular flask of $150 \mathrm{~mL}$; to this, HCI-KCI buffer solution (pH: 2.0-4.0) was added; next, $0.1 \mathrm{~mL}$ of pepsase $(1 \mathrm{~g} / 100 \mathrm{~mL})$ was added, vibrated in a water bath of $60^{\circ} \mathrm{C}$ for $1 \mathrm{~h}$, and cooled down to room temperature; the $\mathrm{pH}$ was regulated to 5.4. Furthermore, $2 \mathrm{~mL}$ of $1 \%$ high temperature-resistant $\alpha$-amylase was added and vibrated in water bath of $90^{\circ} \mathrm{C}$ for $1.5 \mathrm{~h}$, and the starch paste was enzymolized into small molecular dextrin. Next, the sample was cooled to room temperature, and $\mathrm{pH}$ was regulated to $4.1-4.3$; to this, $1 \mathrm{~mL}$ of $0.01 \%$ glucose amylase was added, vibrated in water bath of $40^{\circ} \mathrm{C}$ for $12 \mathrm{~h}$ to completely hydrolyze the dextrin into mannose, and absolute ethyl alcohol with 4 times the volume for alcohol precipitation was added; this solution was centrifuged at $4000 \mathrm{rpm}$ for $20 \mathrm{~min}$, the supernatant was removed, and the sediment was washed with $80 \%$ ethyl alcohol thrice to thoroughly remove glucose; $2 \mathrm{~mol} / \mathrm{L} \mathrm{KOH}$ was used to dissolve the sediment; $\mathrm{pH}$ was regulated to $4.1-4.3$, and $1 \mathrm{~mL}$ of $0.01 \%$ glucoamylase was added. Moreover, the solution was hydrolyzed at $40^{\circ} \mathrm{C}$ for $45 \mathrm{~min}$, heated in boiling water bath for $5 \mathrm{~min}$, and centrifuged at $4000 \mathrm{rpm}$ for $20 \mathrm{~min}$, and the supernatant was collected; distilled water was used to wash the sediment twice and centrifuged, and all the supernatants were combined; next, water was added to a constant volume of $100 \mathrm{~mL}$. The reducing sugar content in the supernatant was determined according to Section 1, the resistant starch content was obtained by multiplying the data by 0.9 [11], and the yield of resistant starch was calculated accordingly:

$$
Y(\%)=\frac{M \times 0.9}{M_{0}} \times 100 \%,
$$

where $Y$ is the yield of resistant starch, $M$ is the content of reducing sugar, and $M_{0}$ is the mass of dry basis of sorghum before and after fermentation.

\subsubsection{Determination of Digestibility of Fermented Sorghum-} Resistant Starch. The research on the digestibility of fermented sorghum-resistant starch samples was conducted based on the method of Yao [12].

(1) Preparation of Artificial Simulated Gastric Juice. The artificial gastric juice was prepared based on the method of Ding [13]. The specific operation was to measure $16.4 \mathrm{~mL}$ of dilute hydrochloric acid, add $800 \mathrm{~mL}$ of distilled water and $10 \mathrm{~g}$ of pepsin, and finally set the volume to $1000 \mathrm{~mL}$.

(2) Preparation of Artificial Simulated Intestinal Fluid. Artificial intestinal fluid was prepared based on the method of Ding Yongbo, the specific operation was to measure $6.8 \mathrm{~g}$ of potassium dihydrogen phosphate, add $500 \mathrm{~mL}$ of distilled water to dissolve, adjust the $\mathrm{pH}$ to 6.8 with $0.1 \mathrm{moL} / \mathrm{L}$ sodium hydroxide solution, and reserve; weigh $10 \mathrm{~g}$ of pancreatin and then add distilled water to dissolve, mix the two liquids, and add water to make up to $1000 \mathrm{~mL}$.
(3) Determination of In Vitro Digestibility of Fermented Sorghum-Resistant Starch. Based on the in vitro digestion model proposed by Dimantov, a certain amount of starch and resistant starch samples were weighed and immersed in simulated artificial gastric juice and artificial small intestine fluid and shaken in a $37^{\circ} \mathrm{C}$ water bath, and the supernatant was taken as a sample at different time periods $(0,60,90120$, 180 , and $240 \mathrm{~min}$ ), and the 3,5-dinitrosalicylic acid method was taken to determine the reducing sugar content in the supernatant and calculate the digestibility:

$$
\text { digestibility }=\frac{0.9 \times \text { glucose content }}{\text { sample content }} \times 100 \% .
$$

2.3.6. Resistant Starch Purification of Naturally Fermented Sorghum. The roughly extracted sorghum-resistant starch was prepared before and after fermentation using $20 \%$ resistant starch milk, and the $\mathrm{pH}$ was adjusted to 5.4; to this, $2 \mathrm{~mL}$ of $1 \%$ high temperature-resistant $\alpha$-amylase was added, and the solution was vibrated in a water bath of $90^{\circ} \mathrm{C}$ for $1.5 \mathrm{~h}$ to enzymolyze the starch paste into monosaccharides and oligosaccharides. Next, the solution was heated in boiling water bath for $10 \mathrm{~min}$, and $95 \%$ ethyl alcohol of four times the volume was added to dissolve the monosaccharides and oligosaccharides. This solution was then centrifuged at $3000 \mathrm{rpm}$ for $20 \mathrm{~min}$ after alcohol precipitation for $4 \mathrm{~h}$, the supernatant was removed, and $10 \mathrm{~mL}$ of $95 \%$ ethyl ethanol was added for precipitation 2-3 times; next, this sample was dried at $50^{\circ} \mathrm{C}$ to a constant weight, crushed, and screened with a 100-mesh sieve; the precipitated purified sorghumresistant starch was obtained [14].

\subsubsection{Effect of Natural Fermentation on Sorghum-Resistant Starch Molecular Structure}

(1) Effect of Fermentation on Sorghum-Resistant Starch Molecular Weight. Sample treatment method: $10 \mathrm{mg}$ of purified resistant starch was weighed, and $1 \mathrm{~mL}$ of $90 \%$ DMSO was added to dissolve at $100^{\circ} \mathrm{C}$ and preserved overnight; to this, $3 \mathrm{~mL}$ of absolute ethyl alcohol was added, the solution was centrifuged, and the supernatant was removed; the sediment was further washed with absolute ethyl alcohol twice. Furthermore, $3 \mathrm{~mL}$ of $1 \mathrm{~mol} / \mathrm{L} \mathrm{NaNO}_{3}(0.02 \%$ $\mathrm{NaN}_{3}$ included) was added and allowed to react for $20 \mathrm{~min}$ at $121^{\circ} \mathrm{C}$ and then centrifuged for $10 \mathrm{~min}$ at $12,000 \mathrm{rpm}$; about $100 \mu \mathrm{L}$ of supernatant was collected for sample loading. The sample data are analyzed with ASTRA6.1 software [15].

Detection conditions: mobile phase: $0.1 \mathrm{~mol} / \mathrm{L} \mathrm{NaNO}_{3}$ (0.02\% $\mathrm{NaN}_{3}$ included), flow velocity: $0.4 \mathrm{~mL} / \mathrm{min}$, and column temperature: $60^{\circ} \mathrm{C}$. Type of analytical column: Ohpak SB-804 HQ and Ohpak SB-806 HQ. Loading quantity of sample: $100 \mu \mathrm{L}$.

(2) Effect of Fermentation on Molecular Functional Group of Sorghum-Resistant Starch. About 0.5-2 mg of purified resistant starch was taken, and 100-200 mg of milled and dried $\mathrm{KBr}$ powder was added, mixed, and ground evenly; the sample was then scanned in the beam of Fourier infrared 
spectrometer, scanning range: $4000-400 \mathrm{~cm}^{-1}$, and resolution: $4 \mathrm{~cm}^{-1}$. The infrared spectra of sorghum-resistant starch before and after fermentation were obtained [16].

(3) Effect of Fermentation on Sorghum-Resistant Starch Molecular Chain Length Distribution. In general, $2 \mathrm{mg}$ of purified resistant starch was weighed and resuspended with $500 \mu \mathrm{L}$ of $95 \%$ ethanol; to this, $4.5 \mathrm{~mL}$ of deionized water was added. The solution was heated in boiling water bath for $60 \mathrm{~min}$ and discontinuously mixed by vortexing; about $2.5 \mathrm{~mL}$ of the sample was collected, and $10 \mu \mathrm{L}(1000 \mathrm{U} / \mu \mathrm{L})$ of isoamylase was added for debranching. The samples were subpackaged in $600 \mu \mathrm{L}$ in each tube and dried in vacuum at $20-25^{\circ} \mathrm{C}$, and $25 \mu \mathrm{L}$ of the dissolved sample was injected into ICS-5000 with PAD detector and PA-1 chromatographic column. The leaching speed was $0.5 \mathrm{~mL} / \mathrm{min}$. The peak areas corresponding to different chain lengths were analyzed by PeakNet software.

Chromatographic conditions: mobile phase: $\mathrm{NaOH} /$ $\mathrm{NaAC}$, flow velocity: $0.5 \mathrm{~mL} / \mathrm{min}$, column temperature: $30^{\circ} \mathrm{C}$, type of chromatographic column: PA1, and loading quantity of sample: $25 \mu \mathrm{L}$.

(4) Effect of Fermentation on the Degree of Crystallinity of Sorghum-Resistant Starch. X-ray diffractometer analysis conditions: characteristic ray: $\mathrm{CuKa}$, power: $1600 \mathrm{~W}$, tube flow: $40 \mathrm{mV}$, tube pressure: $4.0 \times 10^{4} \mathrm{~V}$, scanning speed: $4^{\circ} / \mathrm{min}$, scanning range: $2 \theta=3-60^{\circ}$, step length: $0.02^{\circ}$, DS-SS-RS, respectively, set as $1 \mathrm{~mm}-1 \mathrm{~mm}-0.1 \mathrm{~mm}$ [17]. X'pert HighScore software was used to calculate the crystallinity, and the corresponding curve was derived.

(5) Effect of Fermentation on Particle Morphology of Sorghum-Resistant Starch. The evenly dispersed sorghum starch sample was fixed with conductive adhesive, ion sputtering coating instrument was used for gold sputtering, and scanning electron microscope was used to observe and capture the representative images [18].

\subsubsection{Study on In Vitro Fermentation Property of Fermented Sorghum-Resistant Starch}

(1) In Vitro Fermentation Experiment. About $50 \mathrm{~mL}$ of fecal suspension of healthy adults was collected and transferred into $5 \mathrm{~mL}$ phosphate buffer $(0.1 \mathrm{~mol} / \mathrm{L}, \mathrm{pH}$ 6.5) test tubes with $2.0 \mathrm{~g} / \mathrm{L}, 4.0 \mathrm{~g} / \mathrm{L}$, and $8.0 \mathrm{~g} / \mathrm{L}$ sorghum-resistant starch and sorghum starch. Phosphate buffer without resistant starch was used as a control group. The tubes were well plugged and shaken and were placed in a constant-temperature incubator at $37^{\circ} \mathrm{C}$ and, respectively, sampled for analysis at 6,12 , and $24 \mathrm{~h} \mathrm{[19].}$

(2) Determination of Short-Chain Fatty Acids. The shortchain fatty acids in the fermentation broth were analyzed with gas chromatography [20]. The operating conditions of gas chromatography were HP7673 automatic sample injector, flame ionization detector (FID), capillary column chromatography (HP-5.30 $\mathrm{m} \times 0.32 \mathrm{~mm} \times 0.25 \mu \mathrm{m})$, carrier gas: $\mathrm{N}_{2}$, flow rate: $0.6 \mathrm{~mL} / \mathrm{min}$, split ratio: $50: 1$, sample injection temperature: $250^{\circ} \mathrm{C}$, hydrogen FID temperature: $250^{\circ} \mathrm{C}$, initial column temperature: $100^{\circ} \mathrm{C}$, and raised to $200^{\circ} \mathrm{C}$ at a rate of $2^{\circ} \mathrm{C} / \mathrm{min}$ and maintained for $20 \mathrm{~min}$.

About $3 \mathrm{~mL}$ of sample fermentation broth was collected at different incubation periods and was quickly centrifuged $\left(4^{\circ} \mathrm{C}, 10,000 \times \mathrm{g}, 10 \mathrm{~min}\right)$; from this, $100 \mu \mathrm{L}$ of supernatant was mixed with $280 \mu \mathrm{L} \mathrm{HClO}_{4}$ solution $(0.36 \mathrm{~mol} / \mathrm{L})$ and $270 \mu \mathrm{L} \mathrm{NaOH}$ solution $(1 \mathrm{~mol} / \mathrm{L})$, respectively. The solutions were fully vibrated, and $50 \mu \mathrm{L}$ of phosphate buffer was added and vibrated evenly; moreover, $300 \mu \mathrm{L}$ of methanol solution containing $1 \%$ concentrated $\mathrm{H}_{2} \mathrm{SO}_{4}$ was added. The backflow was observed at $70^{\circ} \mathrm{C}$ for $30 \mathrm{~min}$; next, $300 \mu \mathrm{L}$ of cold $n$ hexane was added to extract short-chain fatty acid methyl ester (FAME), and $2 \mu \mathrm{L}$ of organic layer was considered for gas chromatography analysis.

2.3.9. Data Statistical Analysis. Excel 2016 and SPSS 19.0 software were used for statistical analysis of the data, Origin 8.0 software was used for drawing processing, and the data were measured thrice to obtain the average value.

\section{Result and Analysis}

\subsection{Effect of Natural Fermentation on Content of Sorghum- Resistant Starch}

3.1.1. Preparing Glucose Standard Curve. The glucose standard curve is drawn as in Figure 1, and the regression equation marking the curve is $y=0.1095 x-0.1285$ and $R^{2}=0.9973$.

3.1.2. Effect of Fermentation on the Yield of Sorghum-Resistant Starch. It can be seen from Table 1 that the yield of resistant starch is higher than that of unfermented resistant starch after fermentation. Resistant starch is formed in two stages: the hydrolysis of starch and recrystallization of amylose; hence, the yield of resistant starch is positively correlated with the content of amylose in sorghum [21]. Through the natural fermentation of sorghum, the organic acids, enzymes, and other substances produced in the fermentation process can degrade the protein and fat-wrap the surface of sorghum starch granules, so as to reduce the steric hindrance among the starch granules and fully expose them. Meanwhile, the accumulation of organic acids in the fermented substrate forms empty holes on the surface of starch granules, thereby dissolving the amylose wrapped in the starch granules. Amylase and other substances produced by the fermentation degrade the starch molecules to different degrees, thereby weakening or destroying the amorphous region, that is, noncrystalline region of starch granules, and fully dissolving out the amylose and increasing the retrogradation value. Therefore, the content of sorghum amylose and the yield of sorghum-resistant starch can be greatly increased by natural fermentation pretreatment, making it easier to produce sorghum-resistant starch. 




Figure 1: Glucose standard curve.

TABLE 1: Effect of fermentation on yield of sorghum-resistant starch.

\begin{tabular}{lcc}
\hline Sample & $\begin{array}{c}\text { Unfermented sorghum- } \\
\text { resistant starch }\end{array}$ & $\begin{array}{c}\text { Fermented sorghum- } \\
\text { resistant starch }\end{array}$ \\
\hline Yield (\%) & $35.28 \pm 1.25 a$ & $41.36 \pm 0.89 b$ \\
\hline
\end{tabular}

3.2. Determination of In Vitro Digestibility of Fermented Sorghum-Resistant Starch. Taking sorghum raw starch as a reference, the effect of fermentation pretreatment on digestibility characteristics of sorghum-resistant starch is further investigated by measuring changes in the digestibility of sorghum-resistant starch prepared in human gastric juice and intestinal juice before and after fermentation pretreatment in terms of time. The results are shown in Table 2: as the sorghum raw starch prolonged in the gastric juice and intestinal fluid, starch hydrolyzed to a certain extent, and the digestibility is higher than $13 \%$ at $240 \mathrm{~s}$, which further proves that the digestibility of sorghum raw starch is higher. The sorghumresistant starch samples prepared before and after fermentation under the artificial gastric juice acidic environment are shaken for $60 \mathrm{~s}$, and the sample digestibility is 0 . The digestibility of the sorghum-resistant starch after fermentation pretreatment is still 0 when hydrolyzing for $90 \mathrm{~s}$. It is concluded that the structure of the sorghum-resistant starch prepared after fermentation is more compact, which makes it more difficult for $\mathrm{H}+$ to penetrate inside of the sample to hydrolyze glycosidic bonds and more resistant to erosion by acidic environments and resistance to hydrolysis. In the simulated human small intestine environment, when the digestion time is $0-240 \mathrm{~s}$, the digestibility is $0-4.36 \%$ and digestion rate is lower, which further reflects the digestibility of sorghum-resistant starch. However, after fermentation pretreatment, the sorghum amylose content increased, and resistant starch prepared by the autoclaved complex enzyme method causes recrystallization of amylose reducing the probability of pancreatic amylase binding to enzyme binding sites in resistant starch. Therefore, enzyme resistance reduced digestion rate of samples [22].

\subsection{Effect of Natural Fermentation on Sorghum-Resistant Starch Molecular Structure}

3.3.1. Effect of Fermentation on Sorghum-Resistant Starch Molecular Weight. In the process of pressure-heat compound enzyme method-based preparation of resistant starch, after the pressure-heat treatment, most hydrogen bonds in the crystalline region of the starch molecules are destroyed, thus opening the double helix structure of amylose chains and making pullulanase hydrolyze the $\alpha-1,6$ glucoside bonds of starch in a more concentrated and efficient way [23]. During cooling and retrogradation course, the amylose molecules with different hydrolyzed lengths further fold, wind, and curl and experience molecular rearrangement to form stable double helix structure resistant to enzymolysis [24].

As can be seen from Table 3, the weight-average and number-average molecular weights of the resistant starch molecules prepared by the pressure-heat compound enzyme method were lower than those of the raw starch. The research results were similar to those reported by Zhao and Lin [25]. The content of amylose in sorghum was significantly increased after the fermentation pretreatment, and the molecular weight of the resistant starch prepared was higher than that of the unfermented resistant starch. Fermented sorghum-resistant starch macromolecules increased in percentage content, whereas low-molecularweight substances decreased. This was because fermentation increases the percentage content of sorghum amylose, and pressure-heat treatment breaks the amylose chains. Much amylose of different chain lengths is produced; hence, the content of macromolecules, that is, long-chain amylose content is enhanced. The molecular weight distribution of resistant starch is an important parameter for the characterization of polymer molecular chain length, usually expressed in $M_{\mathrm{w}} / M_{\mathrm{n}}$ (polydispersity index). When $M_{\mathrm{w}} / M_{\mathrm{n}}$ is closer to 1 , it indicates that the component of the sample is simpler, and the molecular weight distribution is more simplified [26]. The big dispersity index of polydisperse and broad-range polymers suggests complicated components of sorghum-resistant starch. The content of fermented sorghum-resistant starch is lower than that of unfermented resistant starch, indicating a more uniform resistant starch system and simpler components after fermentation.

3.3.2. Effect of Fermentation on the Functional Group of Sorghum-Resistant Starch. Infrared spectroscopy is divided into functional group region and fingerprint region, and its frequency ranges are $4000-1300 \mathrm{~cm}^{-1}$ and $1300-400 \mathrm{~cm}^{-1}$ [27]. It is widely used as it is sensitive to the helical structure of starch molecules, the conformation of molecular chains, and the change in crystallinity [28]. Infrared spectroscopy analysis was conducted for the resistant starch before and after fermentation pretreatment, and the scanning spectrogram is as follows.

Figure 2 presents that resistant starch before and after fermentation prepared with pressure-heat compound enzyme method has an absorption peak at $1020 \mathrm{~cm}^{-1}$, suggesting the formation of hydrogen bonds in the sorghum starch aging process [29]. At the same time, before and after fermentation pretreatment, sorghumresistant starch revealed a small change in the amplitudes of amorphous region characteristic absorption at 
TABLE 2: Determination of in vitro digestibility of fermented sorghum-resistant starch.

\begin{tabular}{|c|c|c|c|c|c|c|}
\hline \multirow{3}{*}{ Time (min) } & \multicolumn{6}{|c|}{ Digestibility (\%) } \\
\hline & \multicolumn{3}{|c|}{ Simulated gastric fluid } & \multicolumn{3}{|c|}{ Simulated intestinal fluid } \\
\hline & Native starch & Unfermented RS & Fermented RS & Native starch & Unfermented RS & Fermented RS \\
\hline 0 & $0 \pm 0 a$ & $0 \pm 0 a$ & $0 \pm 0 a$ & $0 \pm 0 a$ & $0 \pm 0 a$ & $0 \pm 0 a$ \\
\hline 60 & $5.814 \pm 0.124 a$ & $0 \pm 0 b$ & $0 \pm 0 b$ & $6.748 \pm 0.857 a$ & $0 \pm 0 b$ & $0 \pm 0 b$ \\
\hline 90 & $8.426 \pm 0.216 a$ & $0.537 \pm 0.088 b$ & $0 \pm 0 c$ & $9.138 \pm 0.685 a$ & $0.833 \pm 0.146 b$ & $0 \pm 0 c$ \\
\hline 120 & $10.15 \pm 1.257 a$ & $1.322 \pm 0.106 b$ & $0.251 \pm 0.032 c$ & $12.21 \pm 1.231 a$ & $2.724 \pm 0.573 b$ & $0.210 \pm 0.072 c$ \\
\hline 180 & $12.73 \pm 0.335 a$ & $1.537 \pm 0.143 b$ & $0.807 \pm 0.112 c$ & $14.25 \pm 1.457 a$ & $3.357 \pm 0.362 b$ & $1.014 \pm 0.535 c$ \\
\hline 240 & $13.35 \pm 0.814 a$ & $3.413 \pm 0.264 b$ & $1.175 \pm 0.097 c$ & $15.58 \pm 1.164 a$ & $4.361 \pm 0.249 b$ & $2.241 \pm 0.845 c$ \\
\hline
\end{tabular}

TABLe 3: Determination of molecular weight of sorghum starch and resistant starch.

\begin{tabular}{|c|c|c|c|c|c|c|c|}
\hline \multirow[b]{2}{*}{ Sample } & \multirow[b]{2}{*}{$M_{\mathrm{n}}(\mathrm{g} / \mathrm{mol})$} & \multirow[b]{2}{*}{$M_{\mathrm{w}}(\mathrm{g} / \mathrm{mol})$} & \multirow[b]{2}{*}{$M_{\mathrm{w}} / M_{\mathrm{n}}$} & \multicolumn{4}{|c|}{ Molecular weight distribution (\%) } \\
\hline & & & & $\begin{array}{l}<1 \times 10^{3} \\
(\mathrm{~g} / \mathrm{mol})\end{array}$ & $\begin{array}{c}1 \times 10^{3}-1.0 \times 10^{4} \\
(\mathrm{~g} / \mathrm{mol})\end{array}$ & $\begin{array}{c}1.0 \times 10^{4}-1.5 \times 10^{4} \\
(\mathrm{~g} / \mathrm{mol})\end{array}$ & $\begin{array}{c}>1.5 \times 10^{4} \\
(\mathrm{~g} / \mathrm{mol})\end{array}$ \\
\hline Native starch & $\begin{array}{l}1.826 \times 10^{6} \\
( \pm 1.072 \%) \mathrm{a}\end{array}$ & $\begin{array}{l}8.022 \times 10^{6} \\
( \pm 0.830 \%) \mathrm{a}\end{array}$ & $4.393( \pm 1.356 \%) \mathrm{a}$ & 0 & 0 & 0 & 100 \\
\hline $\begin{array}{l}\text { Unfermented } \\
\text { RS }\end{array}$ & $\begin{array}{l}8.994 \times 10^{3} \\
( \pm 3.412 \%) b\end{array}$ & $\begin{array}{l}1.462 \times 10^{4} \\
( \pm 2.020 \%) \mathrm{b}\end{array}$ & $1.626( \pm 4.796 \%) b$ & 0 & 46.07 & 21.32 & 32.61 \\
\hline $\begin{array}{l}\text { Fermented } \\
\text { RS }\end{array}$ & $\begin{array}{l}1.099 \times 10^{4} \\
( \pm 1.781 \%) \mathrm{c}\end{array}$ & $\begin{array}{l}1.743 \times 10^{4} \\
( \pm 1.094 \%) \mathrm{c}\end{array}$ & $1.586( \pm 2.465 \%) b$ & 0 & 34.45 & 22.42 & 43.14 \\
\hline
\end{tabular}

Note. Values with different letters in columns are significantly different $(P<0.05)$ from each other.

$1630 \mathrm{~cm}^{-1}$, carbonyl adsorption peak at $1417 \mathrm{~cm}^{-1}$, and hydroxyl absorption peak at $3400 \mathrm{~cm}^{-1}$, illustrating no big effect of fermentation on the crystal-type ranking in the sorghum aging process. According to the spectrogram, the peak patterns revealed no significant difference before and after the preparation of resistant starch and only the intensity of absorption peaks changed slightly, indicating that no new chemical bonds were produced, and no new groups changed or disappeared in the preparation of resistant starch. This suggests that sorghum starch is a physically modified starch.

\subsubsection{Effect of Fermentation on the Distribution of Branched} Chain Length in Sorghum-Resistant Starch. According to Eerlingen's [30] speculation, the formation of resistant starch needs a certain amount of amylose to provide certain spatial three-dimensional structure; if the amylose molecules are too few, the 3D structure cannot be provided so that RS cannot be formed. In fermented sorghum starch, branched chain molecules debranch to form a large number of amylose molecules, increasing the ratio of amylose molecules and making it easier to get resistant starch.

Branched chain was debranched by isoamylase, and the chain length distribution of branched chain in sorghumresistant starch before and after fermentation was, respectively, determined by high-performance anion exchange chromatography-pulse amperometric detection. According to Table 4, before and after fermentation, the branched chain of resistant starch saw a considerable change of its chain length distribution. After fermentation, the DP6-24 polymerization degree of branched chain in resistant starch increased. That is because, in the process of raw material fermentation, the accumulated organic acid amylases cut the internal structure of sorghum starch, shortening its chain length and reducing its intermolecular steric hindrance, thereby contributing to pullulanase debranching. This is why fermented highly resistant starch sees a higher percentage content of DP6-24 in branched chain than unfermented starch.

3.3.4. Effect of Fermentation on the Crystallinity of SorghumResistant Starch. Starch is a typical polycrystalline polymer. Its crystal structure can be divided into four types: type A, type $B$, type $C$, and type $V$. The antienzymolysis properties of different starch crystal types is in the following order: type A $<$ type $\mathrm{B}<$ type $\mathrm{C}<$ type $\mathrm{V}[31$ ].

The X-ray diffraction results of sorghum-resistant starch preparation based on fermentation pretreatment and pressure-heat compound enzyme method are as follows: according to Figure 3, raw sorghum starch is of typical type A crystalline structure, i.e., special diffraction peaks when $2 \theta$ is $15^{\circ}, 17^{\circ}, 18^{\circ}$, and $23^{\circ}$, while the sorghum-resistant starch before and after fermentation both had special diffraction peaks when $2 \theta$ is $12^{\circ}, 17^{\circ}, 20^{\circ}$, and $22^{\circ}$. This indicated that the crystal structure of sorghum-resistant starch had not been significantly changed by fermentation pretreatment. After the sorghum starch was treated with pressure-heat compound enzyme, the characteristic diffraction peak at $2 \theta=15^{\circ}$ disappeared, but the characteristic diffraction peak at $2 \theta=15^{\circ}$ was retained, which is the characteristic diffraction peak of type A crystal; at this time, new diffraction peaks appeared at $2 \theta=12^{\circ}$ and $20^{\circ}$, which is the characteristic diffraction peak of type $\mathrm{V}$ crystal [32], fully demonstrating that the crystal structure of sorghum starch was completely 




(a)

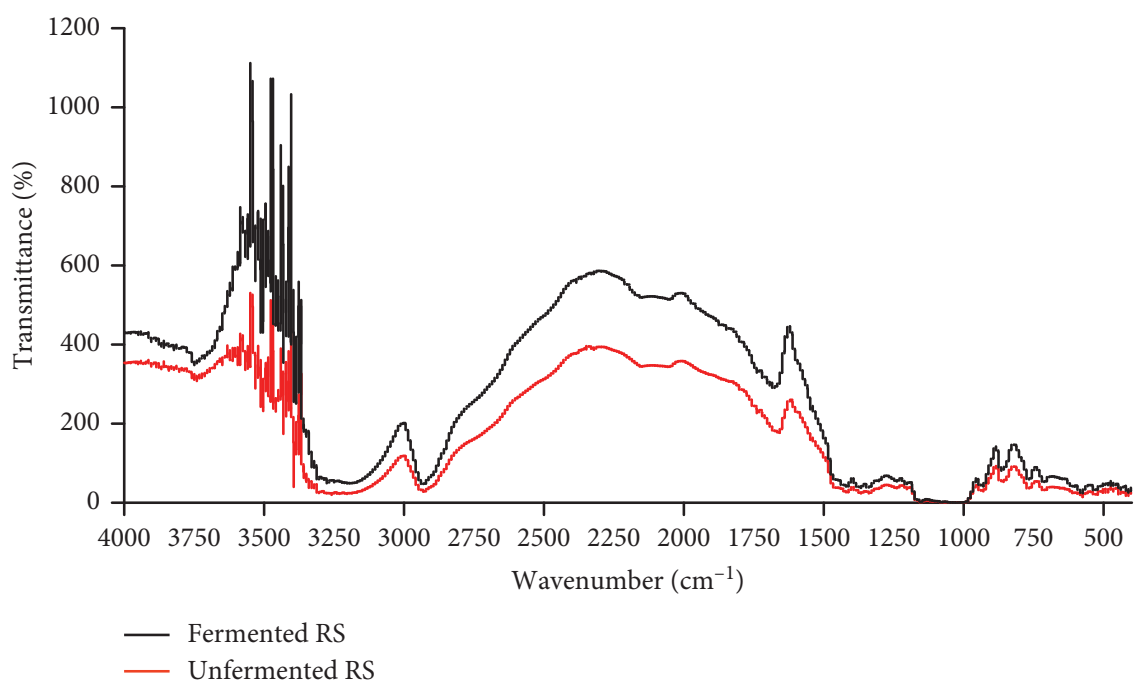

(b)

FIGURE 2: FTIR map of sorghum and resistant starch.

TABLE 4: Distribution of branched chain length in sorghum and resistant starch.

\begin{tabular}{lcccc}
\hline \multirow{2}{*}{ Sample } & & \multicolumn{2}{c}{ Distribution of polymerization degree \% } & DP $\geqq 60$ \\
& DP6-24 & DP25-40 & 13.00 & 1.85 \\
Native starch & 62.40 & 22.75 & 3.36 & 1.77 \\
Unfermented RS & 87.75 & 7.12 & 1.41 & 0.64 \\
Fermented RS & 95.07 & 2.69 & . \\
\hline
\end{tabular}

destroyed after the pressure-heat enzyme treatment and forming type $\mathrm{A}+\mathrm{V}$ crystal structure, thus generating the antienzymatic hydrolysis performance.

It can be seen from Table 5 that the decrease in crystallinity indicates that the crystallinity of resistant starch is less than that of the raw starch. The crystallinity of fermented sorghum-resistant starch is lower than that of unfermented sorghum-resistant starch. The reason may be that the organic acids and enzymes produced in the fermentation process destroy the crystalline region of sorghum starch, thus reducing the crystallinity.

3.3.5. Effect of Fermentation on the Particle Surface Morphology of Sorghum-Resistant Starch. The changes in surface morphology of sorghum-resistant starch particles after fermentation pretreatment are presented in Figure 4. It can be seen from the figure that the original sorghum starch 


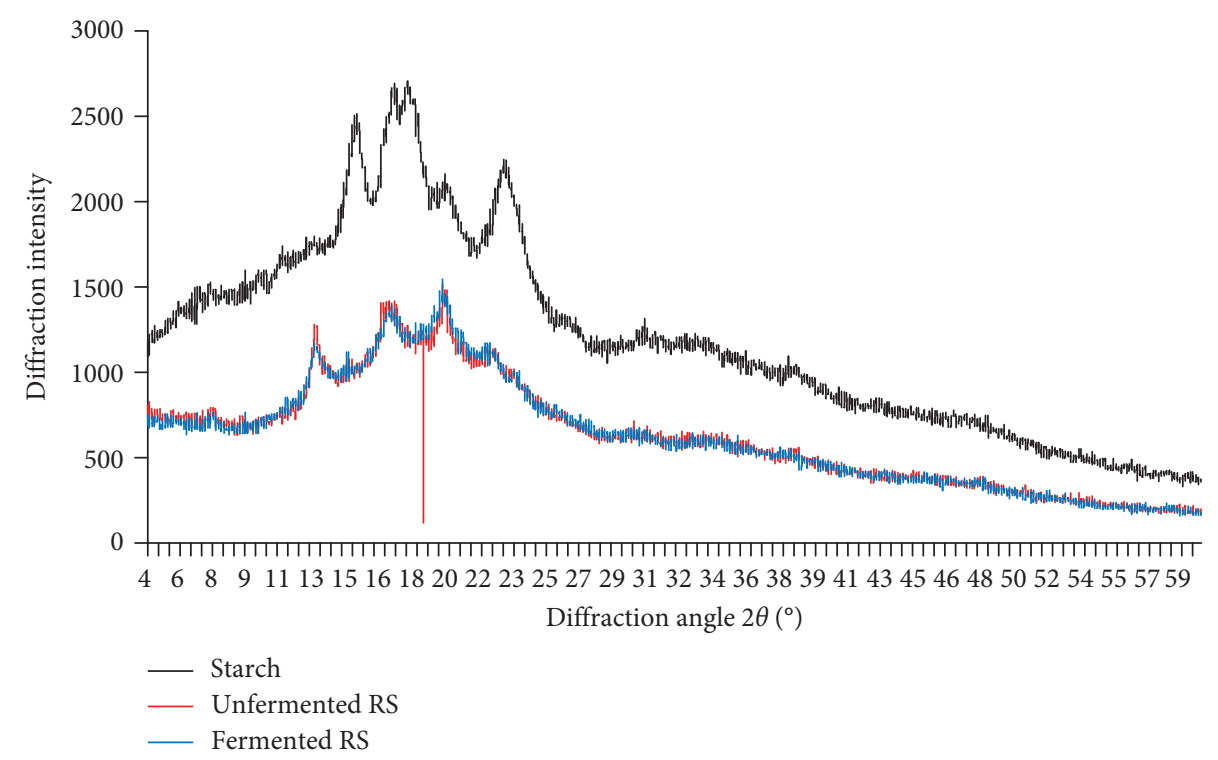

FIGURE 3: X-ray diffraction patterns of sorghum starch and resistant starch.

TABLE 5: X-diffraction $2 \theta$ angle and peak width of sorghum starch and resistant starch.

\begin{tabular}{lcccc}
\hline & Peak serial number & Native starch & Unfermented RS & Fermented RS \\
\hline & 1 & $15.191 \pm 0.002 a$ & $12.841 \pm 0.001 b$ & $12.841 \pm 0.006 b$ \\
Angle of diffraction $2 \theta\left(^{\circ}\right)$ & 2 & $17.373 \pm 0.005 a$ & $17.206 \pm 0.005 b$ & $17.208 \pm 0.004 b$ \\
& 3 & $18.213 \pm 0.002 a$ & $20.056 \pm 0.003 b$ & $20.059 \pm 0.002 b$ \\
& 4 & $23.248 \pm 0.005 a$ & $22.577 \pm 0.005 b$ & $22.241 \pm 0.001 b$ \\
Grating space (d) & 1 & $5.8276 \pm 0.002 a$ & $6.7998 \pm 0.004 b$ & $6.8883 \pm 0.002 b$ \\
& 2 & $5.1003 \pm 0.004 c$ & $5.1496 \pm 0.002 b$ & $5.2000 \pm 0.004 a$ \\
Crystallinity (\%) & 3 & $4.8671 \pm 0.002 a$ & $4.4230 \pm 0.002 b$ & $4.4230 \pm 0.005 b$ \\
\hline
\end{tabular}

Note. The difference between the lowercase letters is unsignificant, and the difference between the lowercase letters is significant.

particles are irregular spheres with a concave surface, with few possessing honeycomb-like structure on the surface. The research result is consistent with that of Tian et al. [33]. After pressure-heat compound enzyme treatment, the sorghum starch particles witness a great change in their morphology: the original spheres completely disappear, forming surface flakes scattered and distributed; the main body below the surface has its laminated structure exposed; after fermentation pretreatment, the laminated structure on the surface of sorghum-resistant starch becomes more uniform in size, and its packing mode is tidier, denser, and completely covers the surface. Scanning electron microscopy (SEM) presents deep or shallow strip-shaped grooves on the surface of sorghum-resistant starch, which are caused by amylose escaping from particles, branched chain disappearing in the crystalline region, and recombination of amylose among particles in the course of pressurized gelatinization [34].

\subsection{Effect of Fermentation on the In Vitro Fermentation} Property of Sorghum-Resistant Starch. Resistant starch cannot be digested and absorbed by the small intestine and can only be fermented in the large intestine to produce a certain content of short-chain fatty acids and lactates. Table 6 presents the determination results of short-chain fatty acids produced by resistant starch of different concentrations $(2.0,4.0$, and $8.0 \mathrm{~g} / \mathrm{L})$ in different fermentation times $(6,12$, and $24 \mathrm{~h})$ in the simulated environment of the adult intestine.

Resistant starch is degraded under the effect of adult intestinal microorganisms into four short-chain fatty acids: formic acid, acetic acid, propionic acid, and butyric acid, among which acetic acid holds the highest content, whereas formic acid has the lowest. The total content of acetic acid, propionic acid, and butyric acid is about $95 \%-98 \%$ of the total amount of short-chain fatty acids. The research result is in contrast to that of Mortensen [35] because of different experimental raw materials used. The fermentation liquors with different concentrations of the same resistant starch presented an increase in the content of short-chain fatty acids as the fermentation time was extended; the increase in degree grew with the concentrations. When the resistant starch concentration increased, it provided enough carbon sources for the metabolism of anaerobic bacteria in feces so as to increase the content of short-chain fatty acid in glycolysis products. The total amount of short-chain fatty acids 




(a)

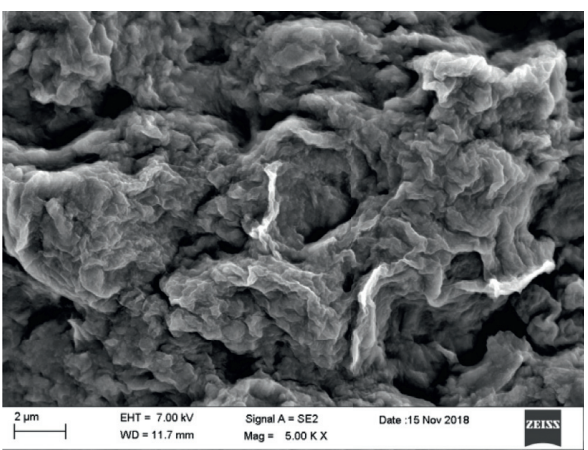

(b)

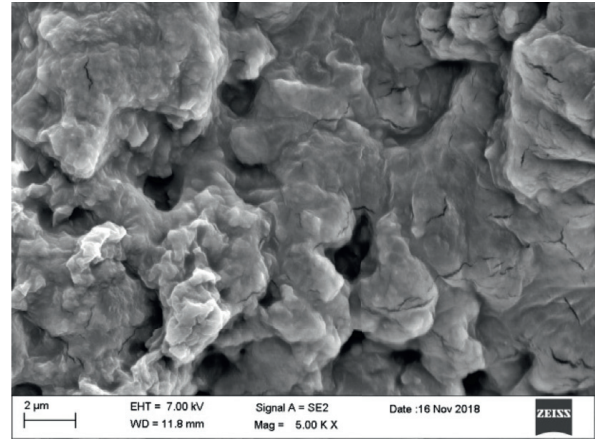

(c)

FIGURE 4: Grain morphology of sorghum starch and resistant starch: (a) native starch; (b) unfermented RS; (c) fermented RS.

TABLE 6: Acid production of sorghum starch and resistant starch in simulated human intestine.

\begin{tabular}{|c|c|c|c|c|c|c|c|c|c|}
\hline \multirow[b]{2}{*}{ Sample } & \multirow[b]{2}{*}{$\begin{array}{c}\text { Sample } \\
\text { concentration } \\
(\mathrm{g} / L)\end{array}$} & \multirow[b]{2}{*}{$\begin{array}{l}\text { Fermentation } \\
\text { time (h) }\end{array}$} & \multicolumn{7}{|c|}{ Short-chain fatty acids (SCFA, $\mu \mathrm{mol} / \mathrm{mL}$ ) } \\
\hline & & & Lactic acid & $\begin{array}{l}\text { Formic } \\
\text { acid }\end{array}$ & Acetic acid & $\begin{array}{l}\text { Propionic } \\
\text { acid }\end{array}$ & Butyrate & Total SCFA & $\begin{array}{c}\text { Butyrate/ } \\
\text { total } \\
\text { SCFA }(\%)\end{array}$ \\
\hline \multirow{9}{*}{ Starch } & \multirow{3}{*}{0.2} & 6 & $1.28 \pm 0.12 c$ & $0.12 \pm 0.01 a$ & $6.30 \pm 0.75 b$ & $2.53 \pm 0.42 a$ & $0.91 \pm 0.68 a$ & $9.86 \pm 1.86 a$ & 9.23 \\
\hline & & 12 & $0.08 \pm 0.08 a$ & $0.05 \pm 0.05 a$ & $7.95 \pm 0.42 a$ & $3.71 \pm 0.32 b$ & $1.46 \pm 0.76 a$ & $13.17 \pm 1.55 a$ & 11.09 \\
\hline & & 24 & $0.01 \pm 0.07 a$ & $0.05 \pm 0.10 b$ & $9.71 \pm 0.62 a$ & $4.58 \pm 0.55 a$ & $1.80 \pm 0.86 a$ & $16.14 \pm 2.13 a$ & 11.15 \\
\hline & \multirow{3}{*}{0.4} & 6 & $0.99 \pm 0.22 c$ & $0.11 \pm 0.01 a$ & $6.01 \pm 0.44 b$ & $3.20 \pm 0.47 b$ & $0.99 \pm 0.38 a$ & $10.31 \pm 1.3 a$ & 9.60 \\
\hline & & 12 & $0.05 \pm 0.14 c$ & $0.12 \pm 0.01 a$ & $8.67 \pm 0.55 b$ & $4.12 \pm 0.72 a$ & $1.68 \pm 0.64 a$ & $14.59 \pm 1.92 a$ & 11.51 \\
\hline & & 24 & $0.12 \pm 0.08 b$ & $0.08 \pm 0.03 a$ & $11.1 \pm 0.32 b$ & $4.84 \pm 0.53 b$ & $2.33 \pm 0.64 a$ & $18.65 \pm 1.52 a$ & 12.49 \\
\hline & \multirow{3}{*}{0.8} & 6 & $1.81 \pm 0.03 c$ & $0.11 \pm 0.08 b$ & $7.60 \pm 0.88 a$ & $3.30 \pm 0.41 a$ & $1.36 \pm 0.44 a$ & $12.37 \pm 1.81 a$ & 10.99 \\
\hline & & 12 & $0.33 \pm 0.25 c$ & $0.14 \pm 0.01 a$ & $9.61 \pm 0.65 a$ & $4.53 \pm 0.32 a$ & $2.09 \pm 0.58 a$ & $16.37 \pm 1.56 a$ & 12.77 \\
\hline & & 24 & $0.14 \pm 0.16 c$ & $0.16 \pm 0.05 b$ & $1.34 \pm 0.54 b$ & $5.53 \pm 0.47 a$ & $1.12 \pm 0.61 b$ & $8.15 \pm 1.67 a$ & 13.74 \\
\hline \multirow{9}{*}{$\begin{array}{l}\text { Unfermented } \\
\text { RS }\end{array}$} & \multirow{3}{*}{0.2} & 6 & $2.30 \pm 0.14 a$ & $0.03 \pm 0.03 b$ & $7.47 \pm 0.27 a b$ & $4.00 \pm 0.88 b$ & $0.94 \pm 0.41 a$ & $12.44 \pm 1.59 b$ & 7.56 \\
\hline & & 12 & $0.22 \pm 0.03 b$ & $0.25 \pm 0.12 a$ & $9.27 \pm 0.89 b$ & $3.40 \pm 0.37 b$ & $1.50 \pm 0.22 a$ & $14.42 \pm 1.6 b$ & 10.40 \\
\hline & & 24 & $0.08 \pm 0.21 b$ & $0.24 \pm 0.01 a$ & $9.72 \pm 0.24 a$ & $5.46 \pm 0.49 a$ & $1.85 \pm 0.86 a$ & $17.27 \pm 1.6 b$ & 10.71 \\
\hline & \multirow{3}{*}{0.4} & 6 & $4.66 \pm 0.33 a$ & $0.22 \pm 0.04 b$ & $9.71 \pm 0.62 a$ & $4.80 \pm 0.48 b$ & $0.89 \pm 0.69 a$ & $15.62 \pm 1.83 b$ & 5.70 \\
\hline & & 12 & $3.24 \pm 0.25 a$ & $0.12 \pm 0.02 a$ & $10.4 \pm 0.73 a b$ & $5.80 \pm 0.27 b$ & $1.17 \pm 0.64 b$ & $17.49 \pm 1.66 b$ & 6.69 \\
\hline & & 24 & $1.02 \pm 0.16 a$ & $0.21 \pm 0.02 b$ & $12.3 \pm 0.58 a$ & $7.18 \pm 0.64 a$ & $1.89 \pm 0.28 a$ & $21.58 \pm 1.52 b$ & 8.76 \\
\hline & \multirow{3}{*}{0.8} & 6 & $8.44 \pm 0.34 b$ & $0.41 \pm 0.05 b$ & $11.7 \pm 0.78 b$ & $5.07 \pm 0.63 b$ & $0.74 \pm 0.45 b$ & $17.92 \pm 1.91 b$ & 4.13 \\
\hline & & 12 & $8.38 \pm 0.25 b$ & $0.04 \pm 0.02 b$ & $12.8 \pm 0.88 b$ & $5.78 \pm 0.48 b$ & $0.92 \pm 0.78 b$ & $19.54 \pm 2.16 b$ & 4.71 \\
\hline & & 24 & $8.91 \pm 0.12 b$ & $0.11 \pm 0.02 a$ & $14.0 \pm 0.47 a$ & $6.16 \pm 0.44 a$ & $0.78 \pm 0.39 a$ & $21.05 \pm 1.32 b$ & 3.71 \\
\hline \multirow{9}{*}{ Fermented RS } & \multirow{3}{*}{0.2} & 6 & $1.58 \pm 0.03 b$ & $0.14 \pm 0.01 c$ & $7.81 \pm 0.92 b$ & $4.29 \pm 0.62 b$ & $0.80 \pm 0.42 b$ & $13.04 \pm 1.97 c$ & 6.13 \\
\hline & & 12 & $0.14 \pm 0.07 c$ & $0.08 \pm 0.12 a$ & $9.16 \pm 1.12 b$ & $5.26 \pm 0.56 b$ & $1.43 \pm 0.87 a$ & $15.93 \pm 2.67 c$ & 8.98 \\
\hline & & 24 & $1.21 \pm 0.17 c$ & $0.14 \pm 0.06 b$ & $9.93 \pm 0.72 b$ & $5.47 \pm 0.67 a$ & $2.10 \pm 0.42 b$ & $17.64 \pm 1.87 b$ & 11.90 \\
\hline & \multirow{3}{*}{0.4} & 6 & $3.35 \pm 0.23 b$ & $0.12 \pm 0.04 c$ & $8.44 \pm 0.62 a$ & $4.57 \pm 0.44 a$ & $1.08 \pm 0.42 b$ & $14.21 \pm 1.52 c$ & 7.60 \\
\hline & & 12 & $1.48 \pm 0.11 b$ & $0.15 \pm 0.05 a$ & $10.3 \pm 1.12 a$ & $5.95 \pm 0.57 b$ & $1.76 \pm 0.33 c$ & $18.16 \pm 2.07 c$ & 9.69 \\
\hline & & 24 & $0.17 \pm 0.06 b$ & $0.05 \pm 0.12 c$ & $11.3 \pm 0.68 a b$ & $6.55 \pm 0.42 a$ & $2.64 \pm 0.75 a$ & $20.54 \pm 1.97 b$ & 12.85 \\
\hline & \multirow{3}{*}{0.8} & 6 & $9.55 \pm 0.17 a$ & $3.18 \pm 0.11 a$ & $12.8 \pm 0.73 c$ & $5.03 \pm 0.62 b$ & $0.77 \pm 0.64 b$ & $21.78 \pm 2.1 c$ & 3.54 \\
\hline & & 12 & $1.01 \pm 0.12 a$ & $0.09 \pm 0.16 b$ & $13.7 \pm 0.85 b$ & $5.73 \pm 0.84 b$ & $0.89 \pm 1.22 b$ & $20.41 \pm 3.07 c$ & 4.36 \\
\hline & & 24 & $10.3 \pm 0.3 a$ & $0.23 \pm 0.11 c$ & $13.8 \pm 0.52 c$ & $5.98 \pm 0.42 a$ & $0.72 \pm 0.62 a$ & $20.73 \pm 1.67 c$ & 3.47 \\
\hline
\end{tabular}

Note. Values with different letters in columns are significantly different $(P<0.05)$ from each other. 
in the fermentation broth with the same resistant starch concentration revealed the same increase in rate; that is, the total amount of short-chain fatty acids increased significantly from 6 to $12 \mathrm{~h}$, whereas the amount increased slightly after $12 \mathrm{~h}$ because fermentation occurred between 6 and $12 \mathrm{~h}$, the logarithmic growth period of total anaerobic bacteria featuring the highest biological activity and the fastest fermentation rate. The content of butyric acid produced by fermentation of sorghum-resistant starch prepared by fermentation pretreatment was higher than that obtained from unfermented sorghum-resistant starch, and the total amount of short-chain lipid acids produced by fermentation was higher than that obtained from unfermented-resistant starch. Relevant studies have revealed that butyric acid of mmol level can inhibit the proliferation and differentiation of cancer cells and reduce the degree of malignancy of cells. Therefore, fermentation pretreatment not only makes it easier to prepare resistant starch but also generates a higher fermentation rate, which can be used as a good food source for human intestinal bacteria to produce butyric acid.

\section{Conclusion}

This paper discusses the effect of fermentation pretreatment on the yield, molecular structure, and fermentation property of sorghum-resistant starch by naturally fermenting sorghum raw material for 8 days, followed by pressure-heat compound enzyme method-based sorghum-resistant starch preparation. By comparing with unfermented resistant starch, we observed that fermentation pretreatment can increase the content of sorghum-resistant starch and make the size of laminated structure on particle surface more uniform. Fermentation pretreatment reduces digestibility of sorghum-resistant starch. FTIR detection suggests that no new chemical groups are produced in the sorghum-resistant starch after fermentation pretreatment, and the peak of its functional group remains unchanged; however, the weightaverage molecular weight and the short-chain branches of branched chain increase, while the percentage content of long-chain branches decrease. The decreased crystallinity of resistant sorghum starch indicates that the crystalline region of sorghum starch is destroyed by fermentation. The in vitro fermentation test reveals that fermented sorghum-resistant starch observes the highest contents of butyric acid and short-chain fatty acids in the fermentation broth of resistant sorghum starch. This study, through fermentation pretreatment combined with pressure-heat compound enzyme method-based sorghum-resistant starch preparation, has found an increased yield of resistant starch, more uniform size of laminated structure on particle surface, and bigger molecular weight. Meanwhile, in vitro simulated adult fermentation experiments have found a higher fermentation rate, higher biological activity, and better functional food sources.

\section{Data Availability}

The data used to support the results of this study are available from the appropriate author.

\section{Conflicts of Interest}

The authors declare that there are no conflicts of interest regarding the publication of this paper.

\section{Acknowledgments}

The authors thank Longkui Cao for helping them with the experimental design and Weihao Wang and Meng Shen for helping them with the revision of the manuscript. This study was funded by the National key Research and Development plan (Grant no. 2017YFD0401203), Heilongjiang Provincial Agricultural Reclamation Bureau Science and Technology Project (Grant no. HNK135-05-02), and Heilongjiang Bayi Agricultural University Graduate Innovation Research Project (Grant no. YJSCX2018-Y53).

\section{References}

[1] Y. Liu, J. L. Duan, W. Q. Li, M. Q. Zhang, and Y. J. Ju, "Study on antioxidant activities of different solvent extracts from the sorghum rice," Journal of the Chinese Cereals and Oils Association, vol. 28, no. 6, pp. 36-39, 2013.

[2] M. Liu, Y. X. Liu, M. Zhang, B. Tan, H. Z. Tan, and X. H. Tian, "Effect of process parameters of twin-screw extrusion on die pressure and the quality properties of white sorghum-based expanded products," Science and Technology of Food Industry, vol. 30, no. 6, pp. 95-101, 2009.

[3] K. O. Adebowale and B. I. Olu-Owolabi, "Effect of heat moisture treatment and annealing on physicochemical properties of red sorghum starch," African Journal of Biotechnology, vol. 4, no. 9, pp. 928-933, 2005.

[4] I. A. G. Hassan and A. H. E. Tinay, "Effect of fermentation on tannin content and in-vitro protein and starch digestibilities of two sorghum cultivars," Food Chemistry, vol. 53, no. 2, pp. 149-151, 1995.

[5] J. W. Devries, "Dietary fiber: the influence of definition on analysis and regulation," Journal of AOAC International, vol. 87, no. 3, pp. 682-706, 2004.

[6] Y. Ge, Z. Kang, M. Sheng, W. H. Wang, and L. K. Cao, "Effect of natural fermentation on physical and chemical properties of sorghum starch," Journal of the Chinese Cereals and Oils Association, vol. 33, no. 7, pp. 51-57, 2018.

[7] E. O. Abd, B. S. Elkhalifa, S. Burkhard, and B. Rita, "Selected physicochemical properties of starch lsolated from fermented sorghum flour," Starch, vol. 56, pp. 582-585, 2004.

[8] F. Zhu, "Buckwheat starch: structures, properties, and applications," Trends in Food Science \& Technology, vol. 49, pp. 121-135, 2016.

[9] C. Bao, The Structural Characteristic of Semen Coicis (Coix Lachryma-Jobi) Resistent Starch and its Mechanism in Regulating Intestinal Flora, Fujian Agriculture and Forestry University, Fuzhou, China, 2017.

[10] A. J. Cormick, M. D. Cramer, and D. A. Watt, "Sink strength regulates photosynthesis in sugar-cane," New Phytologist, vol. 171, pp. 759-770, 2006.

[11] I. Goñi, L. García-Diz, E. Mañas, and F. Saura-Calixto, "Analysis of resistant starch: a method for foods and food products," Food Chemistry, vol. 56, no. 4, pp. 445-449, 1996.

[12] H. Yao, Preparation, Physicochemical Properties and Application Research of Chestnut Resistant Starch, Beijing Forestry University, Beijing, China, 2016. 
[13] Y. B. Ding, Preparation and Characterization of Retrograded Starch Nanoparticles and Chemically Modified Starch Nanoparticles, Southwest University, Chongping, China, 2018.

[14] H. Zhang and Z. Jin, "Preparation of resistant starch by hydrolysis of maize starch with pullulanase," Carbohydrate Polymers, vol. 83, no. 2, pp. 865-867, 2011.

[15] F. F. Li, X. G. Li, Y. Fa et al., "Determination of molecular weight and molecular weight distribution of polyacrylamide with gel permeation chromatography-eighteen angles laser light scattering method," Chemical World, vol. 57, no. 8, pp. 481-486, 2016.

[16] H. T. Tao, The Physico-Chemical Characteristic Change of Fermentated Rice and the Forming Mechanism of Rice Noodles Quality, Henan University of Technology, Zhengzhou, China, 2013.

[17] P. Ispas-Szabo, F. Ravenelle, I. Hassan, M. Preda, and M. A. Mateescu, "Structure-properties relationship in crosslinked high-amylose starch for use in controlled drug release," Carbohydrate Research, vol. 323, pp. 163-175, 2000.

[18] M. C. Garcia, C. M. L. Franco, M. S. S. Júnior, and M. Caliari, "Structural characteristics and gelatinization properties of sour cassava starch," Journal of Thermal Analysis and Calorimetry, vol. 123, no. 2, pp. 919-926, 2016.

[19] B. Drzikova, G. Dongowski, E. Gebhardt, and A. Habel, "The composition of dietary fibre-rich extrudates from oat affects bile acid binding and fermentation in vitro," Food Chemistry, vol. 90, no. 1-2, pp. 181-192, 2005.

[20] Y. X. Ju and J. S. Li, "Extraction and determination of shortchain fatty acids in biological samples," Chinese Journal of Chromatography, vol. 24, no. 1, pp. 81-87, 2006.

[21] C. Onyango, T. Bley, A. Jacob, T. Henle, and H. Rohm, "Influence of incubation temperature and time on resistant starch type III formation from autoclaved and acid-hydrolysed cassava starch," Carbohydrate Polymers, vol. 66, no. 4, pp. 494-499, 2006.

[22] B. Ian, "Complex carbohydrates and resistant starch," Nutrition Reviews, vol. 54, no. 11, pp. 115-119, 1996.

[23] N. Nakamura, K. Watanabe, and K. Horikoshi, "Purification and some properties of alkaline pullulanase from a strain of Bacillus No. 202-1, an alkalophilic microorganism," Biochimica et Biophysica Acta (BBA)_Enzymology, vol. 397, no. 1, pp. 188-193, 1975.

[24] X. T. Wu, Properties and Prebiotics Effects in Vitro of lotus Seed Resistant Starch Prepared by Different Methods, Fujian Agriculture and Forestry University, Fuzhou, China, 2015.

[25] X.-H. zhao and Y. Lin, "The impact of coupled acid or pullulanase debranching on the formation of resistant starch from maize starch with autoclaving-cooling cycles," European Food Research and Technology, vol. 230, no. 1, pp. 179-184, 2009.

[26] L. Chen, X. Y. Li, L. Li, G. Q. Liu, and J. Y. Su, "Molecular mass and conformation of corn starches with ddifferent amylose/ amylopectin ratios," Food Science, vol. 31, no. 19, pp. 157-160, 2010.

[27] P. Bernazzani, V. K. Peyyavula, S. Agarwal, and R. K. Tatikonda, "Evaluation of the phase composition of amylose by FTIR and isothermal immersion heats," Polymer, vol. 49, no. 19, pp. 4150-4158, 2008.

[28] A. Htoon, A. Shrestha, and B. Flanagan, "Effects of processinng high amylose maize starches under controlled condition on structural organisation and amylase digestibility," Carbohydrate Polymers, vol. 75, no. 5, pp. 236-245, 2009.

[29] A. F. Morales, M. J. Estrada, and R. M. Escobedo, "Determination of the structural changes by FT-IR, Raman, and
CP/MAS 13C NMR spectroscopy on retrograded starch of maize tortillas," Carbohydrate Polymers, vol. 87, pp. 61-68, 2012.

[30] R. C. Eerlingen, M. Deceuninck, and J. A. Delcour, "Enzyme resistant starch influence of amylase chain length on resisitent starch formation," Cereal Chemistry, vol. 70, no. 3, pp. 345350, 1993.

[31] A. Buléon, P. Colonna, V. Planchot, and S. Ball, "Starch granules: structure and biosynthesis," International Journal of Biological Macromolecules, vol. 23, no. 2, pp. 85-112, 1998.

[32] A. Lopez-Rubio, B. M. Flanagan, A. K. Shrestha, M. J. Gidley, and E. P. Gilbert, "Molecular rearrangement of starch during in vitro digestion: toward A better understanding of enzyme resistant starch formation in processed starches," Biomacromolecules, vol. 9, no. 7, pp. 1951-1958, 2008.

[33] X. H. Tian, B. Tan, H. Z. Tan, and M. Liu, "Properties of sorghum starches from twenty varieties in China," Food Science, vol. 31, no. 15, pp. 13-21, 2010.

[34] S. Naguleswaran, T. Vasanthan, R. Hoover, and D. Bressler, "Amylolysis of amylopectin and amylose isolated from wheat, triticale, corn and barley starches," Food Hydrocolloids, vol. 35, no. 1, pp. 686-693, 2014.

[35] P. B. Mortensen and M. R. Clausen, "Short-chain fatty acids in the human colon: relation to gastrointestinal health and disease," Scandinavian Journal of Gastroenterology, vol. 31, no. sup216, pp. 132-148, 1996. 